\title{
Trends of Energy and Macronutrients Intakes in Jordan as Obtained by Household Expenditure and Income Surveys
}

\author{
Refa'at Alkurd ${ }^{1}$, Hamed R. Takruri' ${ }^{2} \&$ Amira M. Amr ${ }^{3}$ \\ ${ }^{1}$ Department of Nutrition, Faculty of Pharmacy and Medical Sciences, University of Petra, Jordan \\ ${ }^{2}$ Department of Nutrition and Food Technology, Faculty of Agriculture, The University of Jordan, Jordan \\ ${ }^{3}$ Department of Public Health Nutrition, Faculty of Public Health, Al-Quds University, Jerusalem, Palestine \\ Correspondence: Refa'at Alkurd, Department of Nutrition, Faculty of Pharmacy and Medical Sciences, \\ University of Petra, Jordan. Tel: 962-798-072-776. E-mail: ralkurd@uop.edu.jo
}

Received: September 3, 2018

Accepted: October 15, $2018 \quad$ Online Published: December 15, 2018

doi:10.5539/jas.v11n1p191

URL: https://doi.org/10.5539/jas.v11n1p191

The research is financed by The University of Jordan.

\begin{abstract}
Jordan has encountered changes in demographic and food consumption patterns during the last few decades as a result of the nutrition transition and westernized food habits. This paper aims to evaluate the trends in energy and macronutrient intakes in Jordan based on the data of Jordan Household Expenditure and Income Surveys (JHEIS) 1992-2010. The amounts of consumed food items were analyzed to estimate the intakes of energy and macronutrients for different governorates using (Food Processor SQL Nutrition and Fitness Software, 2010). The average estimated annual per capita intake ( $\mathrm{kg}$ ) for different food groups in the 2010 survey was the lowest since 1992 for legumes and oils and fats, whereas it was the highest for dairy products and eggs. The 2010 percentage of energy contribution of the food groups was the highest for meat and poultry, fish, and dairy products and eggs; whereas it was the lowest for grains, legumes, and fruits and vegetables. Additionally, there was a trend of increased energy intake in 2010 in comparison with previous JHEIS data. Energy intake of Jordanians has increased in 2010 as compared with average energy intake obtained in previous JHEIS surveys since 1992. In addition, the consumption of foods of animal-origin was increased, whereas the consumption of foods of plant-origin was decreased.
\end{abstract}

Keywords: energy intake, JHEIS, Jordan governorates, macronutrients, food groups

\section{Introduction}

Food security is considered one of the important challenges facing any country; each country is responsible for providing food quantities of high quality from all the food groups and nutrients. Sustainable development goals (SDGs) have been initiated to achieve a world without hunger and malnutrition. For this purpose, there was a need for estimation of the proportion of population facing serious constraints on their ability to obtain safe, nutritious and sufficient food (FAO, IFAD, UNICEF, WFP, \& WHO, 2018). Efforts are being made by different countries of the world to achieve SDGs, in an attempt to have food security; SDG2, which is among the most important of them aims at having zero hunger in 2030 (Badran et al., 2018).

Dramatic changes have occurred in the food consumption pattern in the Eastern Mediterranean region (EMR) countries during the past few decades (Nasreddine et al., 2018; Musaiger, 2011). These changes are due to many factors including changes in the life pattern and socioeconomic situation which led to food transition in the region (Alwan \& Kharabsheh, 2006; Popkin, 2004). Through such changes in food consumption patterns and practices, the incidence of many noncommunicable diseases such as overweight and obesity, diabetes mellitus and cardiovascular diseases have increased (Nasreddine et al., 2018).

In Jordan, Food consumption studies and surveys revealed that the per capita intake of the various food groups and their contribution of energy and nutrients have been changed since the mid of the last century (Alwan \& Kharabsheh, 2006; FAO, 2003). Food subsidizing of some basic food commodities was canceled since 1997 (Shaban, Abu-Ghaida, \& Al-Naimat, 2001). The absolute poverty line has risen to 814 Jordanian Dinars (JD) 
(equivalent to 1163 USD) per individual per year (DOS, 2012). In addition, health indicators have improved: crude death rate decreased to 6 per 1000 population, infant mortality rate also decreased to 17 per 1000 and life expectancy increased to 73.5 years (DOS, 2016). The percentage of urban population increased from 46.3 in 1960 to 82.6 in 2010 and to 90.3 years in 2016, while the percentage of rural population decreased from 53.7 in 1960 to 17.4 in 2010 and to 9.7 in 2016 (DOS, 2016, 2011; FAO, 2003). There was an increase in the consumption of fast foods, diets of high-energy and poor nutrients, number of meals eaten in restaurants and the cost of some important foods such as meats (Nasreddine et al., 2018; Musaiger, 2009; FAO/WHO, 2006).

As a result of these socioeconomic and dietary changes, and due to the increase in poverty line and population count to more than 6 millions (World Bank, 2016; Madanat, Troutman, \& Al-Madi, 2008), Jordan started the interest in developing a policy of population planning. Many sectors began the interest in population planning programs; for example, the Ministry of Health began to provide guidance about family planning to the population (USAID, 2001; DOS, 2009). As a result of these family planning interventions and due to the decline in the fertility rates, population growth rate has decreased from $3.2 \%$ in the second half of the $1990 \mathrm{~s}$ to $2.2 \%$ in 2009 (DOS \& ICF Macro, 2010). Despite this decline in population growth rate and fertility rate, the demographic composition was still young; where the median age was 20.3 years in 2010 (DOS, 2011).

Because of these rapid changes in the demographic structure and the consumption pattern of Jordanians, this paper aims at analyzing the food consumption pattern and calculating the per capita food availability depending on the Household Expenditures and Income Survey (DOS, 2012). This study also aims at comparing the present results with that of similar previous studies based on the Household Expenditures and Income Surveys since 1992.

\section{Materials and Methods}

Data in this paper were based on the Jordanian Household Expenditures and Income Surveys (JHEIS) from 1992 to 2010, which aimed at collecting detailed data on the household expenditures and income. The raw data collection of the last survey extended throughout the year of 2010 (DOS, 2012).

In the JHEIS 2010 survey, the annual per capita food consumption data of a representative sample of all Jordanian households was calculated. The included 13866 households were proportionally distributed among the different governorates of the whole country (Kingdom) using two-stage cluster stratified sampling method. These households included 73490 individuals, by an average of 5.3 capita/household. Males constituted $51.26 \%$ and females $48.74 \%$ of the sample; $40.2 \%$ were children younger than 18 years and $3.8 \%$ were elderly (older than 65 years). A questionnaire was distributed to households included in the study. The questionnaire contained data of the money expenditure on different food and nonfood categories. The data on food items was analyzed using a nutrition analysis software program (Food Processor SQL Nutrition and Fitness Software, 2010) (Food Processor SQL, 2010) which included details on the contents of energy and nutrients for each food item. In case a food item was not included in the database of the mentioned software program, the nutrient content of that food was obtained from other food analysis sources such as Food Composition Tables for Use in the Middle East (Pellet \& Shadarevian, 2013) and Food Composition Tables of the Gulf Region (Musaiger, 2006). Such foods and their analyses were introduced to the Food Processor database. Then the obtained data were compared to the food consumption of the Jordanian Household Expenditures and Income Surveys of the years of 1992 to 2008 (DOS, 1992, 1997, 2002, 2008). Also, consumption values of these foods and nutrients obtained from them were compared among rural and urban areas and among the different governorates of the Kingdom. Statistical analysis was performed with SPSS IBM-20 software. The significance level was set at $P \leq 0.05$. The differences in the rate of annual intake at different food groups and energy consumption over the different years were evaluated using one-way ANOVA tests [Least Significant Difference (LSD) test].

\section{Results}

\subsection{Rates of Annual Intake of Different Food Groups, HEIS 2010}

Table 1 shows the average annual food consumption (kg/capita) of different food groups in Amman (the capital of Jordan), the whole country (Kingdom), rural and urban areas of Jordan according to JHEIS 2010. The table shows the variability in the per capita consumption of different food groups among the rural and urban populations: the consumption rates of the food groups of grains, legumes, meats and poultry, and sugar were significantly higher ( $\mathrm{P}$ $<0.05$ ) in rural areas than in urban ones; whereas, the consumption rates of the food groups of oils and fats, fish, beverages, and other foods were significantly higher $(\mathrm{P}<0.05)$ in urban areas than those in the rural ones. When comparing Amman to the whole country, rural and urban areas, consumption by Amman people was the highest for fruits and vegetables and oils and fats. 
Table 1. Comparison of rates of annual intake ( $\mathrm{kg} /$ capita) of the different food groups in the Kingdom, Rural and Urban areas, and Amman as calculated from the Household Expenditures and Income Survey 2010 ${ }^{1}$

\begin{tabular}{|c|c|c|c|c|c|c|c|c|c|c|c|}
\hline Governorate & Grains & Legumes & $\begin{array}{l}\text { Fruits and } \\
\text { vegetables }\end{array}$ & $\begin{array}{l}\text { Oils and } \\
\text { fats }\end{array}$ & $\begin{array}{l}\text { Meats and } \\
\text { poultry }\end{array}$ & Fish & $\begin{array}{l}\text { Dairy products } \\
\text { and eggs }\end{array}$ & Sugar & Nuts & Beverages & Other foods \\
\hline Kingdom & 174.1 & 5.96 & 195.7 & 16.6 & 60.9 & 4.9 & 51.5 & 43.4 & 2.4 & 136 & 28.28 \\
\hline Urban & 167.58 & 7.12 & 195.79 & 17.2 & 58.59 & 5.04 & 50.63 & 41.57 & 2.54 & 150.63 & 29.63 \\
\hline Rural & 202.34 & 7.85 & 200.66 & 14.67 & 60.28 & 4.4 & 50.46 & 49.23 & 2.27 & 61.97 & 16.56 \\
\hline Amman & 163.11 & 7.77 & 207.32 & 18.64 & 60.92 & 5.9 & 51.18 & 44.67 & 3.05 & 27.82 & 24.24 \\
\hline
\end{tabular}

Note. ${ }^{1}$ DOS, 2012.

\subsection{The Average Annual per Capita Intake of the Different Food Groups During 1992 to 2010}

Table 2 shows the comparison of the 2010 average annual per capita consumption $(\mathrm{kg})$ of the food groups with those of the previous surveys (from 1992 to 2006/2007). It is clear from the 2010 data that it was the lowest for legumes (5.96) and oils and fats (16.6), whereas it was the highest for fish (4.9) and dairy products and eggs (51.5). However, there was no trend in the consumption rates of the other food groups. Again, when comparing the average consumption of 2010 with that of the average consumption of the years 1992 to 2006/2007, it is apparent that there was a decrease in the consumption of grains, legumes, fruits and vegetables, oils and fats and sugar. The lowest decrease was for fruits and vegetables $(0.32 \%)$ and the highest decrease was for oils and fats $(26.79 \%)$. On the other hand, there was an increase in the consumption of fish (38.81\%), and dairy products and eggs (58.8\%).

Table 2. Comparison of the average annual per capita intake of the different food groups as calculated from the Household Expenditures and Income Survey of 1992-2010 for the whole country ${ }^{1}$

\begin{tabular}{|c|c|c|c|c|c|c|c|}
\hline \multirow{2}{*}{ Main food groups } & \multicolumn{5}{|c|}{ Rate of annual consumption(kg/capita) } & \multirow{2}{*}{$\begin{array}{l}\text { Average consumption } \\
\text { of } 1992 \text { to } 2006 / 2007\end{array}$} & \multirow{2}{*}{$\begin{array}{l}\% \text { change of the average } \\
\text { consumption to the } 2010\end{array}$} \\
\hline & 1992 & 1997 & 2002 & $2006 / 2007$ & 2010 & & \\
\hline Sample size & 8000 & 6048 & 12792 & 12768 & 13866 & - & - \\
\hline Grains & 201.1 & 210 & 218.4 & 161.9 & 174.1 & 197.87 & -12 \\
\hline Legumes & 6.9 & 6.9 & 10 & 8.4 & 5.96 & 8.05 & -25.96 \\
\hline Fruits and vegetables & 188 & 188.6 & 213.2 & 195.5 & 195.7 & 196.33 & -0.32 \\
\hline Oils and fats & 22.6 & 22.3 & 22.1 & 23.9 & 16.6 & 22.73 & -26.79 \\
\hline Meat and poultry & 44.5 & 44.2 & 55.7 & 61.5 & 60.9 & 51.48 & 18.3 \\
\hline Fish & 4 & 3.3 & 2.9 & 3.9 & 4.9 & 3.53 & 38.81 \\
\hline Dairy products and eggs & 29.6 & 30.3 & 35.5 & 34.3 & 51.5 & 32.43 & 58.8 \\
\hline Sugar & 44.5 & 39.4 & 74.2 & 33.5 & 43.4 & 47.9 & -9.395 \\
\hline Other foods & 48.9 & 58 & 41 & 32.2 & 28.28 & 45.03 & -37.19 \\
\hline Nuts & - & - & - & 2.6 & 2.4 & - & - \\
\hline Beverages & - & - & - & 82.5 & 136 & - & - \\
\hline
\end{tabular}

Note. ${ }^{1}$ DOS, 1992; DOS, 1997; DOS, 2002; DOS, 2008; DOS, 2012.

\subsection{Trends of Energy Intake During 1992 to 2010}

Table 3 shows the per capita daily energy intake from different food groups. It is clear that the energy intake in 2010 was higher than that in the years 1992 to 2006-2007 for foods of animal origin: meat and poultry, fish, dairy products and eggs, as well as that of oils and fats, sugars, and beverages; whereas it was lower for foods of plant origin: legumes and fruits and vegetables. The percentage of change in 2010, as compared with the average of 1992 to 2006/2007 data shows that there was a positive change (an increase) in the energy of most of food groups and total energy ranging from sugars $(+11.27 \%)$ to beverages $(+70.35 \%)$; while there was a negative change (a decrease) in energy from fruits and vegetables $(-7.26 \%)$, grains $(-7.77 \%)$, and legumes $(-30.25 \%)$. 
Table 3. Trends of energy intake (kcal/capita/day) as calculated from the Household Expenditures and Income Survey of 1992-2010 for the whole country ${ }^{1}$

\begin{tabular}{lllllllll}
\hline \multirow{2}{*}{ Main food groups } & \multicolumn{9}{c}{ Average } & ergy intake (kcal/capita/day) & Average intake of & $\begin{array}{l}\text { \% change of the average } \\
\text { intake of } 2010\end{array}$ \\
\cline { 2 - 6 } & 1992 & 1997 & 2002 & $2006 / 2007$ & 2010 & 1992 to 2006/2007 & - \\
\hline Sample size & 8000 & 6048 & 12792 & 12768 & 13866 & - & -7.77 \\
Grains & 1717 & 1607 & 1555 & 1297 & 1424 & 1544 & -30.25 \\
Legumes & 61 & 48 & 41 & 53 & 35.4 & 50.75 & -7.26 \\
Fruits and vegetables & 231 & 216 & 273 & 228 & 219.8 & 237.0 & +12.07 \\
Oils and fats & 354 & 265 & 390 & 389 & 391.7 & 349.5 & +32.34 \\
Meat and poultry & 221 & 233 & 260 & 223 & 310 & 234.25 & +26.15 \\
Fish & 17 & 15 & 17 & 16 & 20.5 & 16.25 & +37.30 \\
Dairy products and eggs & 143 & 121 & 143 & 171 & 198.4 & 144.5 & +11.27 \\
Sugar & 439 & 376 & 463 & 348 & 452.3 & 406.5 & +79.27 \\
Other foods2 & 217 & 52 & 102 & 229 & 268.9 & $150 *$ & +6.14 \\
Total & 3400 & 2933 & 3217 & 2954 & 3325 & 3132.8 & \\
\hline
\end{tabular}

Note. ${ }^{1}$ DOS, 1992; DOS, 1997; DOS, 2002; DOS, 2008; FAO STAT, 2017.

${ }^{2}$ Other foods in this table include also beverages and nuts.

\subsection{Percent of Contribution of Different Food Groups to the Total Energy Intake During 1992 to 2010}

Table 4 indicates the percent contribution of each food group in the total energy intake during the period of 1992 to 2010. The highest contribution was always for grains, ranging from $43 \%$ to $50.5 \%$ of the total energy intake. Whereas, the lowest contribution was always for fish, ranging from $0.3 \%$ to $0.6 \%$ of the total energy intake. When comparing the \% change of different food groups to the total energy intake in 2010 to that of the average consumption in 1992 to 2007/2007, it is noticed that the highest change was of legumes (+35.29\%) despite its little contribution in the total energy intake; on the other hand, the lowest contribution was of oils and fats $(+1.72 \%)$.

Table 4. Percent of contribution of different food groups to the total energy intake as calculated from the Household Expenditures and Income Survey of 1992-2010

\begin{tabular}{llllllll}
\hline \multirow{2}{*}{ Main food groups } & \multicolumn{5}{c}{ Percentage (\%) } & $\begin{array}{l}\text { Average consumption } \\
\text { of 1992 to 2006/2007 }\end{array}$ & $\begin{array}{l}\text { \% change of the average } \\
\text { consumption to the 2010 }\end{array}$ \\
\cline { 2 - 6 } Sample size & 1992 & 1997 & 2002 & $2006 / 2007$ & 2010 & - \\
Grains & 8000 & 6048 & 12792 & 12768 & 13866 & - & -9.71 \\
Legumes & 50.5 & 47.6 & 48.5 & 43.9 & 43 & 47.63 & -35.29 \\
Fruits and vegetables & 1.8 & 1.9 & 1.3 & 1.8 & 1.1 & 1.70 & -14.47 \\
Oils and fats & 6.8 & 7.4 & 8.5 & 7.7 & 6.5 & 7.60 & +1.72 \\
Meat and poultry & 10.4 & 10.7 & 12.1 & 13.2 & 11.8 & 11.6 & +25.87 \\
Fish & 6.5 & 5.5 & 8.1 & 8.5 & 9.0 & 7.15 & +33.33 \\
Dairy products and eggs & 0.5 & 0.3 & 0.5 & 0.5 & 0.6 & 0.45 & +34.08 \\
Sugar & 4.2 & 4.6 & 4.4 & 4.7 & 6.0 & 4.48 & +6.46 \\
Other foods2 & 12.9 & 13.5 & 14.4 & 11.8 & 14.0 & 13.15 & +29.08 \\
\hline
\end{tabular}

Note. ${ }^{1}$ DOS, 1992; DOS, 1997; DOS, 2002; DOS, 2008; FAO STAT, 2017.

${ }^{2}$ Other foods in this table include also beverages and nuts.

\subsection{Total Energy and Macronutrients Intake and Their Percentage of Energy Contribution in Jordan in 2010}

Table 5 compares the energy contribution of carbohydrates, proteins and fats in the whole country, urban, and rural areas and their percentage of contribution to the total energy intake during 2010. When comparing the rural to urban areas, the rural intakes (in grams) were significantly higher $(P<0.05)$ than that of the urban for all the three macronutrients in addition to the energy intake (in kcal). The percentage rural energy contributions were significantly higher $(P<0.05)$ than that of the urban for carbohydrate and protein, but was significantly lower $(P<$ 
$0.05)$ for fat. When comparing the results of the whole country with that of urban and rural, the whole country intakes were almost significantly $(P<0.05)$ higher than urban and lower than rural.

Table 5. Total energy and macronutrients intake and their percentage of energy contribution for the whole country, rural, and urban populations in Jordan according to DOS, 2012

\begin{tabular}{|c|c|c|c|c|c|c|c|}
\hline \multirow{2}{*}{ Governorate } & \multirow{2}{*}{$\begin{array}{l}\text { Energy intake } \\
\text { (kcal) }\end{array}$} & \multicolumn{2}{|r|}{ Carbohydrate } & \multicolumn{2}{|r|}{ Protein } & \multicolumn{2}{|r|}{ Fat } \\
\hline & & (g) & $\%$ of total energy & (g) & $\%$ of total energy & (g) & $\%$ of total energy \\
\hline The whole country & 3325 & 501 & 60.27 & 110 & 13.22 & 100 & 27.07 \\
\hline Urban & 3204 & 473 & 59.04 & 107 & 13.31 & 101 & 28.22 \\
\hline Rural & 3587 & 584 & 65.07 & 116 & 12.91 & 90 & 22.57 \\
\hline
\end{tabular}

\subsection{Comparison of the Estimated Consumption of Energy in Jordan, 2010 and 2006/2007}

Table 6 compares the daily per capita energy intake (kcal) in the whole country and governorates in 2010 with that of 2006/2007 and the percentage of change between the 2 surveys. Among the 12 governorates, Madaba had the highest energy intake in 2010 (4333 kcal) and also in 2006/2007 (3328 kcal). The energy intakes were decreased in 2010 compared to those of 2006/2007 in Balqa, Irbid, and Ajlun; whereas it did not change in Ma'an.

Table 6. Comparison of the daily per capita estimated consumption of energy (kcal) in the whole country and different governorates in Jordan from 2010 and 2006/2007 data ${ }^{1}$

\begin{tabular}{llll}
\hline Governorate & 2010 & $2006 / 2007$ & \% of change \\
\hline Amman & 3327 & 2940 & 13.2 \\
Balqa & 2921 & 3079 & -5.1 \\
Zarqa & 3272 & 2893 & 13.1 \\
Madaba & 4334 & 3328 & 30.2 \\
Irbid & 3143 & 3320 & -5.3 \\
Mafraq & 3285 & 2876 & 14.2 \\
Jarash & 4290 & 3054 & 40.5 \\
AjIun & 2753 & 3245 & -15.2 \\
Karak & 3925 & 3107 & 26.3 \\
Tafilah & 3235 & 2710 & 19.4 \\
Ma'an & 3074 & 3075 & 0 \\
Aqaba & 2833 & 2750 & 3 \\
Kingdom & 3325 & 3031 & 9.7 \\
\hline
\end{tabular}

Note. ${ }^{1}$ Takruri, Alkurd, \& Faris, 2001.

\subsection{Daily Estimated Consumption of Fat and the Percentage Contribution of Fat to the total Energy Intake in Jordan, 2010 and 2006/2007}

Table 7 compares the daily per capita intake ( $\mathrm{g}$ ) of fat in the whole country and the different governorates for the years 2010 and 2006/2007. The total fat intake in the whole country during 2010 was $100 \mathrm{~g} / \mathrm{capita}$ and the highest intake was in Jarash (126.9 g) and the lowest was in Mafraq (65.4 g). On the other hand, the total fat consumption during 2006/2007 was the highest in Ajlun (112.9 g) and the lowest in Tafilah (64.9 g), whereas the whole country consumption was $(87 \mathrm{~g})$. The table also shows the percentage of contribution of fat to the total energy intake in the whole country and the governorates in 2010 and 2006/2007. Amman, the capital, had the highest percentage of the fat contribution to the total energy intake (29.3\%) in 2010, while it was the third in 2006/2007. On the other hand, Mafraq had the lowest percentage of fat contribution to the total energy intake (17.8\%) in 2010. 
Table 7. Daily per capita estimated consumption of fat and the percentage contribution of fat to the total energy intake in the whole country and the different governorates in Jordan 2010 and 2006/2007

\begin{tabular}{|c|c|c|c|c|}
\hline \multirow{2}{*}{ Governorate } & \multicolumn{2}{|c|}{ Daily intake of fat (g) } & \multicolumn{2}{|c|}{ Contribution of fat $(\%)$ to the total energy intake } \\
\hline & 2010 & $2006 / 2007$ & 2010 & $2006 / 2007$ \\
\hline Amman & 109.9 & 92.5 & 29.3 & 28.3 \\
\hline Balqa & 70.9 & 89.4 & 21.5 & 25.9 \\
\hline Zarqa & 102.9 & 85.3 & 27.5 & 26.4 \\
\hline Madaba & 110.3 & 97.3 & 22.4 & 26.2 \\
\hline Irbid & 97 & 111.4 & 27.4 & 30 \\
\hline Mafraq & 65.4 & 79.2 & 17.8 & 24.7 \\
\hline Jarash & 126.9 & 82.1 & 26.2 & 24 \\
\hline AjIun & 73.4 & 112.9 & 23.7 & 31 \\
\hline Karak & 107.3 & 74.1 & 24.1 & 21.4 \\
\hline Tafilah & 88.7 & 64.9 & 24.4 & 21.5 \\
\hline Ma'an & 108 & 79.4 & 24.4 & 23.1 \\
\hline Aqaba & 85.3 & 75.3 & 26.7 & 24.6 \\
\hline Whole country & 100 & 87 & 26.6 & 25.6 \\
\hline
\end{tabular}

Note. ${ }^{1}$ Takruri \& Alkurd, 2014; FAO, 2003.

\section{Discussion}

Jordan is witnessing a nutrition transition era which results in changes in food habits and adoption of westernized lifestyle with consequent changes in the nutrition status (Musaiger, 2011; Madanat et al., 2008). Therefore, it was thought of benefit to investigate trends of energy and nutrients intakes, based on the data of Jordan Household Expenditure and Income Surveys (JHEIS) 1992-2010.

\subsection{Rates of Annual Intake of Different Food Groups, HEIS 2010}

The figures of Table 1 cannot be interpreted alone. These figures will give a clear picture about the intakes of food groups in Jordan when expressed as energy, carbohydrate, protein, and fat, as shown and discussed in Table 5.

\subsection{The Average Annual Per Capita Intake of Different Food Groups During 1992 to 2010}

The higher intakes of fish, and dairy products and eggs of 2010 compared with those of the previous surveys (1992 to 2006/2007) may be explained by the fact that most of the marketed fish in Jordan is the cheap imported frozen type, and that poultry and eggs are sufficiently produced in the country with relatively cheap price (Tayyem et al., 2016). The intake of these cheap food animal sources and the low intake of plant foods, particularly vegetables and fruits, may be a factor in the increased energy intake in 2010. It should be noted that the wealth of families is a factor in food selection. Unemployment rate, particularly in women, is high; this is reflected on poverty rate. The poverty rate was reported to be $14 \%$ in 2010 and it reached $18.6 \%$ in 2015 according to World Bank data. It should be noted that third of the population in Jordan live below the poverty line, at least one quarter of the year, known as transient poverty (Zureiqat \& Shameh WFP, 2015). Thus, the increase in the consumption of animal foods, especially in urban areas, may be explained by selection of relatively cheaper animal food sources such as eggs and poultry (Tayyem et al., 2016, 2010).

\subsection{Trends of Energy Intake During 1992 to 2010}

Compared to the HEIS 1992 to 2006-2007, the increase in the intakes of 2010 for energy and foods of animal origin accompanied by the decrease of foods of plant origin (i.e., food sources of dietary fibers) is in line with the increasing incidence of obesity and chronic non communicable diseases in Jordan during the same period (Takruri \& Alkurd, 2014; Alwan \& Kharabsheh, 2006). These results are also in agreement with data from the FAOSTAT (2017) (FAO STAT, 2017) which showed that the average dietary energy supply adequacy during the period between 2009 to 2011 was $136 \%$, indicating that there was a surplus of energy available for the whole population. This increase in energy intake might partly explain the high prevalence of overweight, obesity, and related diseases among Jordanians.

\subsection{Percent of Contribution of Different Food Groups to the Total Energy Intake During 1992 to 2010}

The highest energy contribution of grains among other food groups in the consecutive surveys stresses that grains is still the staple food in Jordan. Whereas, the lowest energy contribution of fish indicates that fish is 
still not a traditional food. It should be noted that the increased contribution of fish, dairy products and eggs in the total energy principally reflects a positive change toward healthy eating pattern. On the other hand, the decreased contribution of grains, legumes, and fruits and vegetables in the total energy accompanied by the increased contribution of oils and fats, meat and poultry, sugars and total energy intake can be explained by the change in food habits affected by westernization in the eating pattern (Musaiger, 2011; Alwan \& Kharabsheh, 2006). These results indicate potential health risks because the increased contribution of energy from certain foods is associated with a number of chronic diseases such as heart disease, hypertension, obesity, diabetes, sleep apnea, some cancers and stroke (Goel et al., 2013). This is particularly important if we take these results together with the results of studies conducted by the Ministry of Health which showed high prevalence of these diseases among Jordanians aged 18 years and more. These studies showed that $16 \%$ of Jordanians suffer from diabetes, more than $66 \%$ are overweight or obese, $25.6 \%$ suffer from high blood pressure and $36 \%$ and $48.8 \%$ suffer from high cholesterolemia and triglyceridemia, respectively (Ministry of Health, 2007). More recent data from WHO (WHO, 2015) indicated that the prevalence of overweight and obesity in Jordan were $\geq 30 \%$ and $29 \%$ for females and males, respectively. It is worth mentioning that the obesity is highly prevalent in most Arab countries, despite the disparity in the socioeconomic and cultural aspects (Musaiger, 2010).

\subsection{Total Energy and Macronutrients Intake and Their Percentage of Energy Contribution in Jordan, HEIS 2010}

The macronutrient contributions as percentage of the estimated total energy intakes were within the AMDR which are $45-65 \%, 10-35 \%$, and $20-35 \%$ for carbohydrate, protein, and fat, respectively. As reported by Takruri and his colleagues (Alkurd, 2011; Takruri, Alkurd \& Faris, 2011), the high energy consumption of rural people is probably due mainly to the high consumption of carbohydrate rather than to fat. This result is similar to that of the 2006/2007 food consumption data. The high carbohydrate consumption of rural people in 2010 was mainly due to the high consumption of grains, legumes, and sugar, whereas the low contribution of fat energy by the rural people is probably due to their lower consumption of oils and fat group as indicated by Takruri and Alkurd (2010).

\subsection{Comparison of the Estimated Consumption of Energy in Jordan, 2010 and 2006/2007}

As shown in Table 6, the lowest energy intake was for Ajlun $(2753 \mathrm{kcal})$ in 2010 and for Tafilah $(2710 \mathrm{kcal})$ in $2006 / 2007$, whereas the highest percentage change was for Jarash $(+40.5 \%)$, which is not easy to explain especially that Ajlun and Jarash are very close to each other and people living there are supposed to have the same food habits.

\subsection{Daily Estimated Consumption of Fat and the Percentage Contribution of Fat to the Total Energy Intake in Jordan, 2010 and 2006/2007}

It is noticed that the total fat intake of the whole country in 2010 was higher than that of the 2006/2007 intake by 13 g. There was no constant trend in the intake of fats in the governorates in 2010. In 2010, the percentages of fat intakes relative to the total energy intakes were within the AMDR of fat (20\%-35\%), except for Mafraq which had a fat percentage less than the lower limit of the AMDR. The percentage of intake of fat in 2006/2007 was within the AMDR for all governorates and the whole country.

\section{Conclusion}

It can be concluded that energy intake of Jordanians has increased in 2010 as compared with average energy intakes obtained in previous JHEIS surveys since 1992. In addition, the consumption of foods of animal-origin was increased, whereas the consumption of foods of plant-origin was decreased.

Among the strategies to improve the current relatively high energy intake is to educate people on consuming healthy food choices. This can be achieved by consuming high nutrient density foods (such as vegetable and fruits) and decreasing those foods with high fat and energy contents. Development of national dietary guidelines is important in this regard.

\section{Acknowledgements}

The authors thank the Jordanian Department of Statistics for providing the JHIES data and The University of Jordan for financial support, by offering sabbatical leave for one of the authors (HRT).

\section{References}

Alkurd, R. A. (2011). Estimated intakes of fats, cholesterol, fiber, sodium, calcium, potassium and magnesium in Jordan. Australian Journal of Basic and Applied Sciences, 5, 3171-3178. 
Alwan, A., \& Kharabsheh, S. (2006). Nutrition in Jordan: A review of the Current Nutritional Trends and Major Strategic Directions of the National Food and Nutrition Policy. Ministry of Health, WHO and Ministry of Agriculture, Amman, Jordan.

Badran, I., Taimeh, A., Takruri, H., Abdullah, F., Khasawneh, M., Zreigat, G., \& Bader, H. (2018). Achieving SDG2 in Jordan: A National Strategic Review. The National Center for Research and Development, Amman, Jordan.

DOS \& ICF Macro. (2010). Jordan Population and Family Health Survey 2009. Calverton, Maryland, USA: Department of Statistics and ICF Macro. Retrieved from http://www.dos.gov.jo/dos_home_e/main/ linked-pdf/pop_2009.pdf

DOS (Department of Statistics). (1992). Jordan Population and Family Health Survey. DOS, Amman, Jordan.

DOS (Department of Statistics). (1997). Jordan Population and Family Health Survey. DOS, Amman, Jordan.

DOS (Department of Statistics). (2002). Jordan Population and Family Health Survey. DOS, Amman, Jordan.

DOS (Department of Statistics). (2008). Household Expenditures and Income Survey 2006. DOS, Amman, Jordan.

DOS (Department of Statistics). (2009). Jordan in Figures, 2008 (Issue 11). DOS, Amman, Jordan.

DOS (Department of Statistics). (2011). Jordan in Figures, 2010 (Issue 13). DOS, Amman, Jordan. Retrieved from http://www.dos.gov.jo/dos_home_e/main/jorfig/2010/jor_f_e.htm

DOS (Department of Statistics). (2012). Household Expenditures and Income Survey 2010. DOS, Amman, Jordan.

DOS (Department of Statistics). (2016). Jordan in Figures. DOS, Amman, Jordan.

FAO STAT. (2017). Country Indicators, Jordan. Retrieved from http://www.fao.org/faostat/en/\#country/11

FAO, IFAD, UNICEF, WFP, \& WHO. (2018). The State of Food Security and Nutrition in the World 2018. Building climate resilience for food security and nutrition. Rome, FAO.

FAO. (2003). Jordan Nutrition Country Profile. FAO, Rome.

FAO/WHO. (2006). Technical Consultation on Nutritional Food-Based Dietary Guidelines. WHO Reg. Office, Cairo, Egypt.

Food Processor SQL. (2010). Food Processor nutrition and fitness software. Food Processor SQL Inc., Salem, OR, USA.

Goel, R., Agarwal, A., Shabbir, A., So, J. B. Y., Pasupathy, S., Wong, A., ... Lomanto, D. (2013). Bariatric surgery in Singapore from 2005 to 2009. Asian Journal of Surgery, 36, 36-39. https://doi.org/10.1016/ j.asjsur.2012.08.006

Madanat, H. N., Troutman, K. P., \& Al-Madi, B. (2008). The nutrition transition in Jordan: The political, economic and food consumption contexts. Promotion \& Education, 15, 6-10. https://doi.org/10.1177/ 1025382307088092

Ministry of Health. (2007). The Most Important Results of the Study of Behaviors and Risk Factors for Noncommunicable Diseases. Jordan Ministry of Health in collaboration with the World Health Organization and U.S. Centers for Disease Control, Amman, Jordan.

Musaiger A. O. (2006). Food Composition Tables of Common Foods of Gulf Cooperation Council Countries. Arab Centre for Nutrition, Manama, Bahrain.

Musaiger A. O. (2009). Fast foods. In A. Musaiger (Ed.), Encyclopedia of Arab Food and Nutrition (pp. 710-724). Beirut: Academia.

Musaiger A. O. (2010). Obesity in the Arab countries: prevalence causes and control. In A. Musaiger (Ed.), Proceedings of the Third Arab Conference on Obesity (pp. 10-25). Physical Activity, Bahrain 19-21 Jan, 2010. The Arab Center for Nutrition, Manama, Bahrain.

Musaiger A. O. (2011). Food Consumption Patterns in Eastern Mediterranean Countries. Arab Center for Nutrition Manama, Bahrain.

Pellet, P. L., \& Shadarevian, S. (2013). Food Composition Tables for Use in the Middle East (3rd ed.). AUB, Beirut, Lebanon. 
Popkin, B. M. (2004). The nutrition transition: An overview of world patterns of change. Nutrition Reviews, $62(7$ Pt 2), S140-S143. https://doi.org/10.1111/j.1753-4887.2004.tb00084.x

Shaban, R. A., Abu-Ghaida, D., \& Al-Naimat, A-S. (2001). Poverty Alleviation in Jordan. Lessons for the Future, The World Bank, USA. https://doi.org/10.1596/0-8213-4958-9

Takruri, H. R., \& Alkurd, R. (2014). Intakes of fats, cholesterol, fiber, and micronutrients as risk factors for cardiovascular disease in Jordan. Jordan Journal of Biological Sciences, 7, 119-126. https://doi.org/ $10.12816 / 0008225$

Takruri, H. R., Alkurd, R., \& Faris, M. A. (2011). Trends of the intakes of energy, macronutrients and their food sources in Jordan. Journal of Saudi Society for Food and Nutrition, 6, 40-54.

Tayyem, R. F., Bawadi, H. A., Shawawreh, A., Jad-Allah, H., Abu-Oleim, S. A., \& Khader, Y. S. (2010). Changes in food supply pattern in Jordan from 1961 to 2005. Dirasat, 37, 46-55.

Tayyem, R. F., Bawadi, H. A., Shehadah, I., Abu-Mweis, S. S., Agraib, L. M., Al-Jaberi, T., ... Bani-Hani, K. E. (2016). Meats, milk and fat consumption in colorectal cancer. Journal of Human Nutr Diet, 29, 746-756. https://doi.org/10.1111/jhn.12391

USAID. (2001). A New Roadmap to Guide Family Planning in Jordan. The makings of a national strategy. Retrieved from https://www.healthpolicyproject.com/index.cfm?id=JordanFPSuccessStory

WHO. (2015). Global strategy on diet, physical activity and health. Obesity and Overweight. WHO Press, Geneva.

World Bank. (2016). The World Bank Data/Jordan. Retrieved from https://data.worldbank.org/country/jordan

Zureiqat \& Abu Shameh, W. F. P. (2015). Social Protection and Safety Nets in Jordan, World Food Program in Jordan. Amman, Jordan.

\section{Copyrights}

Copyright for this article is retained by the author(s), with first publication rights granted to the journal.

This is an open-access article distributed under the terms and conditions of the Creative Commons Attribution license (http://creativecommons.org/licenses/by/4.0/). 